\title{
Patrick Cabanel, Jean-Dominique Durand, dirs., Le grand exil des congrégations religieuses françaises,
} 1901-1914

Paris, Le Cerf, coll. « Histoire », 2005, 489 p.

\section{Raymond Courcy}

\section{CpenEdition}

\section{Journals}

Édition électronique

URL : http://journals.openedition.org/assr/3884

DOI : $10.4000 /$ assr.3884

ISSN : $1777-5825$

Éditeur

Éditions de l'EHESS

Édition imprimée

Date de publication : 1 décembre 2006

Pagination : 115-283

ISBN : 2-7132-2124-2

ISSN : 0335-5985

\section{Référence électronique}

Raymond Courcy, « Patrick Cabanel, Jean-Dominique Durand, dirs., Le grand exil des congrégations religieuses françaises, 1901-1914 ", Archives de sciences sociales des religions [En ligne], 136 | octobre décembre 2006, document 136-21, mis en ligne le 12 février 2007, consulté le 21 septembre 2020. URL : http://journals.openedition.org/assr/3884 ; DOI : https://doi.org/10.4000/assr.3884 


\section{Patrick Cabanel, Jean-Dominique Durand, dirs., Le grand exil des congrégations religieuses françaises, 1901-1914}

Paris, Le Cerf, coll. « Histoire », 2005, 489 p.

Raymond Courcy

1 Ce livre est la publication des actes du colloque qui s'est tenu à l'université de Lyon III les 12-13 juin 2003. Il analyse les problèmes posés aux congrégations lorsque, au début $\mathrm{du} \mathrm{xx}^{\mathrm{e}}$ siècle, le gouvernement français a voulu prendre à sa charge les écoles comme les hôpitaux, rompant totalement avec les accords passés depuis le concordat de 1801. Le sujet n'avait pratiquement jamais été abordé. «Que dire de ces laïcisations forcées, des solitudes induites, des bouleversements intimes? Personne apparemment en dehors de ce colloque, n'a cherché à recueillir cette histoire et à la faire vivre [...] Certains silences demeurent à la longue assourdissants.»(Cl. Langlois, p. 168). La plupart des contributions sont d'ailleurs les résultats de travaux de recherche plus que l'expression de synthèses définitives. "Le colloque a labouré un champ de recherche neuf [...] avec la nécessité de traiter des questions parfois jamais abordées. »

Une première partie aborde la législation anticongréganiste qui aboutit en 1904 à l'exclusion complète des religieux et religieuses de toutes les écoles. Comme le dit Jean Bauberot dans ses conclusions, «la lutte anticongréganiste forme une grande part du contexte dans lequel se déroule le processus de séparation de l'Église et de l'État. Elle relève en effet, pour de nombreux laïques, d'un processus d'émancipation à l'égard de la religion et pour les catholiques d'une entreprise de spoliation, de persécution de l'Église. » Le XIX ${ }^{e}$ siècle avait vu un développement extraordinaire des congrégations religieuses consacrées à des œuvres diverses (hôpitaux, aide sociale, assistance et surtout enseignement) qui en principe devaient avoir une autorisation légale selon les normes du concordat. Elles étaient 271 au début de la III ${ }^{e}$ République, un chiffre bien inférieur à la réalité. 
3 En fait, la première étape de la prise en charge de l'enseignement par l'État est la loi Ferry, en 1880, qui rend l'école obligatoire et ouvre les écoles normales pour les instituteurs. Elle entraîne un premier exode qui concerne surtout les congrégations d'hommes non autorisées. Une loi de 1886 proposera une simple déclaration pour obtenir cette autorisation. Mais la fin du xix ${ }^{e}$ siècle, avec l'affaire Dreyfus, va accentuer cette division des deux France et engendrer un climat d'affrontement radical qui durera de l'été 1901 à l'année 1910.

4 La loi votée en 1901 sous le gouvernement Waldeck-Rousseau est une loi saluée par tous aujourd'hui comme une loi de liberté qui permet à tout citoyen de constituer une association. Mais l'article 13 du titre III comporte un volet anticongréganiste. Le but du pouvoir était d'obliger toutes les congrégations, quelles que soient leurs activités, à demander une reconnaissance légale. On affirmait aussi vouloir récupérer le «milliard des congrégations » pour le donner à des œuvres ouvrières. Mais pour « les associations dont les membres vivent en commun ", les applications remettaient en cause l'habit religieux et l'exercice des vœux.

5 Émile Combes, arrivant au pouvoir en 1902, fera de cette loi une interprétation restrictive. Dès le mois de juin, il fera fermer par la force les «écoles irrégulières ». Il parachèvera son action avec la loi du 7 juillet 1904 par laquelle « l'enseignement de tout ordre et de toute nature est interdit en France aux congrégations. » Cet enseignement ne peut être désormais exercé que par des laïques. L'État ne donne plus aucun subside aux congrégations. L'opposition des deux France est alors à son comble.

6 Lorsque Aristide Briand arrive au pouvoir en 1906, il le fait avec un souci de conciliation. Les expulsions s'arrêtent. La déclaration de guerre en 1914 refera l'unité de la France. Le décret Malvy, le jour même où l'Allemagne envahit la Belgique, entraînera "la suspension de toute action administrative ou judiciaire qui serait conduite en application des lois de 1901 et $1904 »$. Beaucoup de religieux reviendront alors au pays. Des arrangements négociés se feront en 1923-1924 sans que pour autant les oppositions entre école laïque et école « libre » soient définitivement réglées.

Une deuxième partie du livre décrit les réactions à ces lois anticongréganistes. La contribution de Jacques-Olivier Bourdon indique, par exemple, que la position des évêques fut loin d'être unanime. Certains émettent des protestations véhémentes, tel l'évêque de Nancy « qui lance un appel à l'union des catholiques et des libéraux contre des mesures qu'ils jugent attentatoires aux libertés ». Mais beaucoup font preuve de modération tels les évêques de Grenoble, Marseille ou Montauban... "L'Église aurait volontiers échangé la suppression des congrégations, voire de l'école libre, contre le maintien du concordat. » (p. 189).

8 Les religieux(ses) sont placé(e)s devant un véritable dilemme. Faut-il rester ou partir? Ils peuvent choisir «l'exil fictif»: la sécularisation. Ils continuent leur œuvre d'enseignement en abandonnant tout signe extérieur de leur consécration (habit, vie communautaire...). Beaucoup feront ce choix devenant des «sœurs costumées en laïques ". Mais beaucoup aussi (environ 30000 ) feront le choix d'un exil effectif. Espérant un retour, ils voulaient échapper à la contrainte légale et demeurer fidèle à leur engagement. «Il est conçu comme le moyen et le signe de la fidélité absolue à la vocation religieuse et à cet outil au service de Dieu que sont les congrégations religieuses." "Je ne peux vivre au milieu d'un monde qui me perdrait." "On ne pouvait rien attendre de bon de la république.» 
C'est aux espaces géographiques de cet exil qu'est consacrée une grande partie de l'ouvrage. Les stratégies de départ et les conditions d'accueil sont différentes selon qu'il s'agira de l'Europe, des Amériques ou encore du «Maghreb et du Levant». Ce ne sont jamais des individus isolés mais des groupes plus ou moins compacts qui sont concernés. Cela demande des démarches parfois difficiles pour trouver des maisons assez conséquentes, obtenir l'autorisation de l'évêque du lieu ou acquérir la permission légale des gouvernements de ces pays où parfois, comme en Italie, il existe des courants anticléricaux.

Pour beaucoup de congrégations, il s'agit de déménager maison généralice ou maison de formation pour les novices : c'est sur l'Europe, principalement en Belgique ou en Italie (à Rome en particulier) que le choix est fait. Il y a aussi la volonté de conserver les œuvres d'éducation. C'est ainsi que nombre de communautés se sont installées avec leur pensionnat tout proche de la frontière du côté de la Belgique, de la Suisse, de l'Italie et de l'Espagne. Ainsi, le seul diocèse de Vintimille a accueilli à peu près quarante communautés et instituts religieux français.

11 La logique de l'exil fut certainement différente pour les Amériques. Beaucoup de congrégations qui émigrèrent alors avaient déjà des maisons dans ces pays. Pour d'autres, ce fut l'occasion de véritables fondations appelées à durer. Les faits sont particulièrement significatifs dans le Québec francophone où près de 2000 religieux(ses) s'installèrent entre 1901 et 1909.

12 La situation est radicalement différente dans les colonies et les protectorats français alors « pays de mission ». De manière paradoxale, l'État français continuera de soutenir et de financer les communautés religieuses. Leurs œuvres sont le vecteur essentiel de la transmission de la culture française. «Le rôle civilisateur de la France est indissociable de l'action des missions.» (p. 310). En conséquence "l'anticléricalisme, c'est pour la France, mais ce n'est pas un article d'exportation » (Gambetta). Les députés catholiques sauront défendre « ces religieux qui apprennent là-bas la langue française et font aimer le nom Français ». Certes il y eut des heures difficiles. La " mission laïque française » fut fondée le 20 décembre 1901, mais n'eut guère qu'un succès temporaire à Madagascar grâce à la ténacité de Victor Augagneur, médecin socialiste et franc-maçon, ancien maire de Lyon, et qui fut gouverneur de l'île de 1905 à 1909. Dès cette dernière année, les subventions du ministère des Affaires étrangères aux écoles missionnaires avaient retrouvé le niveau antérieur à la crise: "Hors des frontières il est donc possible d'enfreindre la loi. » Ceci est particulièrement remarquable au Moyen-Orient où la France, en vertu des accords internationaux, assure la protection des catholiques vivant dans l'Empire ottoman. Le nombre des religieux de toutes les congrégations augmenta notoirement au début du $\mathrm{xx}^{\mathrm{e}}$ siècle. Ainsi, au Liban, où les jésuites ont déménagé leur scolasticat, leur nombre est passé de 110 à 188 entre 1890 et $1904 \ldots$ Et beaucoup de diplomates perçoivent les écoles congréganistes comme le seul moyen efficace dont dispose la France pour étendre son influence sur la population musulmane, car « l'école sans Dieu heurte la piété des musulmans ».

13 Au bout du compte, ce colloque fait apparaître un réel paradoxe : «La loi de 1904 en interdisant la finalité enseignante, supprime aussi ce qui était la raison de vivre, à la veille de la loi Ferry, de près des deux tiers des congréganistes. Or ce séisme s'est opéré sans que les congrégations elles-mêmes, des plus grandes au plus petites, soient vitalement touchées.» Les contraintes de l'exil ne firent qu'accentuer le processus d'expansion missionnaire des congrégations mis en place dès la première moitié du XIX 
siècle et permit une première internationalisation du recrutement jusqu'alors quasi exclusivement d'origine française. « La politique de conciliation [de l'Église de France] avait trouvé ses limites [...] C'est le mystère de l'histoire qui réserve toujours des surprises, le désastre diplomatique ouvrit paradoxalement la voie à un redéploiement à travers le monde de milliers de religieuses et de religieux français et servit le rayonnement mondial de l'Église catholique » (p. 111).

On peut certes souligner le caractère provisoire des conclusions de ces contributions face à la complexité de la réalité et à la diversité des situations. Mais ce livre fera date et sera certainement une référence incontournable pour ceux et celles qui voudront entamer des travaux plus approfondis sur ce " point refoulé de l'historiographie ». 